\title{
Finite Difference Method to Design Sustainable Infiltration Based Stormwater Management System
}

\author{
Thewodros K. Geberemariam \\ P. O. Box 23195 Brooklyn, New York 11202, USA; tgm@nyu.edu
}

\begin{abstract}
:
Infiltration based stormwater best management practices bring considerable economic, social and ecological benefits. Controlling stormwater quantity and quality are primarily important to prevent urban flooding and minimizing loads of pollutants to the receiving waters. However, there have been growing concerns about how the traditional design approach contributes to the failure of infiltration based BMP's that have caused flooding, ponding, prolonged movement of surface water, and frequent clogging, etc. Many of these problems were due to the fact that the current design approaches of stormwater BMP's only focus on surface hydrology and give little or no attention to the underline subsoil permeability rate and other constraints during the design and sizing process. As a result, we are exhibiting many newly constructed infiltration based BMP's are failing to function well. This paper presents and demonstrates a new paradigm shift in designing infiltration-based stormwater BMP's by combining subsurface hydrology and undelaying native soil constraints to establish acceptable criteria for sizing infiltration based BMPs.
\end{abstract}

Keywords: Infiltration based BMP's; Flood; Infiltration; Clogging; Soil permeability; Underdrain; Soil saturation rate; Drainage basin; Urban drainage

\section{INTRODUCTION:}

Infiltration is the rate at which surface water percolates into the ground. It is often expressed as $\mathrm{cm}$ or inches per hour, but the SI amount is m s-1 (Al-Hamati et al 2010; Bauer, 1974; Bouwer et al 1999; Daly et al 2012). The infiltration rate depends on a number of factors including soil type, soil moisture, vegetation, and temperature. Typically, the smaller the grains of soil, the more slowly water percolates into the ground. Also, the wetter the ground, the less room there is for water to infiltrate and consequently, the slower the rate (Emerson \& Traver, 2008; Haverkamp et al, 1977; Griffin \& Warrington, 1988; Guo \& Gao, 2016).

\section{HORTON'S THEORY OF INFILTRATION}

Horton's theory is based on the fact that infiltration is faster in dry ground, so as rain continues and the ground becomes wetter, the infiltration rate decreases. The reason that infiltration is faster when the ground is dry is that there are more spaces for the water to fit so capillary forces that pull the water down into the ground are stronger (Bauer 1974; Beven, 2004; Bouwer et al 1999; Guo, 2003; Guo \& Gao, 2016; Mein \& Larson; 1973; Overton \& Meadows, 1973; Pitt \& Voorhees, 2010; Philip, 1969; Verma, 1982).

$$
\left(f-f_{c}\right)=\left(f_{0}-f_{c}\right) e^{-k t}
$$

Horton's Equation is the governing heuristic equation for infiltration, 
Where:
$f=$ infiltration rate
$f_{0}=$ (initial) infiltration rate for dry ground
$f_{\mathrm{c}}=($ asymptotic) infiltration rate for saturated ground
$k=$ infiltration constant

The infiltration equation is written with $\left(f-f_{c}\right)$ on the left hand side (rather than isolating $f$ ) because it is the excess infiltration rate above the value for saturated ground that diminishes exponentially with time (Pitt \& Voorhees, 2010; Philip, 1969; Verma, 1982).

Integrating Horton's equation over time gives the total depth of water that has infiltrated, $F$,

$$
F(t)=\int f d t=f_{c} t+\frac{\left(f_{0}-f_{c}\right)}{k}\left(e^{-k t}-1\right)
$$

Where:

$F(t)=$ infiltration depth in inch (or $\mathrm{mm})$ at time $\mathrm{t}$.

\section{LIMITS TO HORTON'S THEORY}

Horton's equation and integral assume that the rainfall rate, $R$ is greater than the infiltration rate throughout the rain. If at any time the rainfall rate is slower than the infiltration rate, the ground will lose some water to lower levels, and Horton's theory must be modified (Philip, 1969; Stafford et al 2015; Verma, 1982).

\section{MODEL INFILTRATING STORMWATER}

Infiltration can be modeled by a layer of ground in which water enters through the top at a rate, $f=$ $f_{\text {in }}$ and leaves through the bottom (into the water table) at a rate $f_{\text {out. }}$ As soon as any water is stored in the ground, storage $S>0$ and,

$$
f_{\text {out }}=f_{c}
$$

The depth of water stored in the layer, $S$, is equal to the total depth of infiltration, $F$ minus the depth of water that has leaked out the bottom of the layer. Except in very permeable soil (such as sand or gravel, water leaks out the bottom so slowly, it is safe to assume that during any rainfall,

$$
S=F-f_{c} t
$$

The infiltration rate, $f_{\text {in }}$ is limited by the rainfall rate and by the total amount of stored water in the layer, 


$$
f_{\text {in }}=\min \left[\begin{array}{l}
R \\
\left(f_{0}-f_{c}\right) \frac{\left(S_{\max }-S\right)}{S_{\max }}+f_{c}
\end{array}\right]
$$

$\mathrm{R}=$ Rainfall Rate and $S_{\max }=$ maximum depth of water layer can store

Solving Horton's Equation yields the value for $S_{\max }$

$$
S_{\max }=\frac{f_{0}-f_{c}}{k}
$$

The rate at which water is stored in the layer is equal to the infiltration rate minus the outflow rate through the bottom of the layer, or,

$$
\frac{d S}{d t}=f_{\text {in }}-f_{\text {out }}
$$

The difficulty with this equation is that Eq. (5) for $f_{\text {in }}$ is complicated. If rainfall is ever less than the possible infiltration rate, then it is necessary to solve Eq. (7) numerically, using finite difference techniques (Afrin et al, 2016; Haverkamp et al, 1977; Le Coustumer \& Barraud, 2007; Lewellyn et al, 2015; Mein \& Larson 1973; Murphy 2013; Stafford et al. 2015).

\section{FINITE DIFFERENCE TECHNIQUES}

The secret of finite difference techniques is to replace derivatives by finite differences. This transforms a differential equation into an arithmetic equation that can be solved easily. Solving a differential equation using finite differences involves several steps (Al-Hamati et al 2010; Ferguson 1990; Huyakorn 1984; Krvavica et al 2018; Kunze \& Nielsen 1982; Smith, 1985; Overton \& Meadows 2013; Stafford et al 2015; Zaidel \& Russo 1992).

1. Replace all derivatives with differences.

2. Solve the equation for the unknown (generally the future value).

2. Choose a value for the time step $(\Delta t)$ or a distance interval.

3. Substitute current values to find the future value of the variable.

4. Iterate, or, update by repeating step 3 as much as needed.

The derivative is defined as,

$$
\frac{d S}{d t}=\lim _{\Delta t \rightarrow 0} \frac{S(t+\Delta t)-S(t)}{\Delta t}
$$

The finite difference technique assumes that the difference equals the derivative. Then we write the 
infiltration equation, Eq. (8) in finite difference form and rearrange to solve for $S(t+\Delta t)$ because it is the only unknown (Krvavica et al 2018; Kunze \& Nielsen 1982).

\section{FINITE DIFFERENCE INFILTRATION EQUATION}

$$
S(t+\Delta t)=S(t)+\Delta t\left(f_{\text {in }}-f_{c}\right)
$$

Finally, overland flow occurs when the rainfall rate is greater than the infiltration rate. In that case,

$$
\text { Overland flow }=R-f_{\text {in }}
$$

\section{DETERMINATION OF DESIGN STORAGE VOLUME}

In designing infiltration based BMPs, the native soil infiltration on the land surface and the design rainfall event dictate the storage volume for the basin. Moreover, the soil water storage capacity beneath the basin sets up the limit for the maximum water depth in the basin including the invert elevation of the underdrain pipe. In most of urban area, infiltration basined BMPs are often placed next to a small, highly paved small urban catchments such as parking lots and business strip. Therefore, the volume-based approach is suitable to predict the peak runoff from such a small urban watershed, and to finding the maximum volume difference between the inflow and outflow volumes under a series of storm events with different durations (Al-Hamati et al 2010; Guo, 1996,1999 2001, 2002,2003 and 2004; Liu et al. 2015; Zhang and Guo, 2014). To determine the peak runoff for a small urban watershed, the rational method states:

$$
Q_{d}=\alpha C I_{d} A
$$

Using the Chicago method, the rainfall intensity in equation (11) can be calculated (Keifer \& Chu 1957; Silveira, 2016) as

Where:

$$
I_{d}=\frac{a}{\left(T_{d}+b\right)^{n}}
$$

$\alpha=$ unit conversion factor, equal to 1 for English units, and 1/360 for SI units,

$C=$ runoff coefficient,

$A=$ watershed area in acres (hectare),

$I_{d}=$ rainfall intensity in inch $/ \mathrm{hr}(\mathrm{mm} / \mathrm{hr})$,

$T_{d}=$ rainfall duration in minutes,

$Q_{d}=$ peak runoff rate in $\mathrm{cfs}(\mathrm{cms})$ and

$\mathrm{a}, \mathrm{b}$, and $\mathrm{n}=$ constants on the Intensity- Duration- Frequency (IDF)

Using the above Eq. $(10,11,12)$ we can calculate the maximum volume difference between the inflow and outflow volumes under a series of storm events with different duration (Department of the Army and the Air Force in 1977; Guo, 1999). The inflow runoff volume is determined by the 
net rainfall volume as

$$
V_{i}=\alpha C I_{d} A T_{d}
$$

The outflow volume can be estimated by the sump inlet capacity as

$$
V_{o}=Q F\left(T_{d}\right)
$$

Therefore, the required design storage volume is the difference between Eq. 13 and 14. Aided by equation 1 to 12 , the storage volume, $\mathrm{V}$, is obtained as

$$
V_{d}=\left(\alpha C I_{d} A T_{d}\right)-Q F\left(T_{d}\right)
$$

Where:

$$
\begin{aligned}
& V_{d}=\text { Design storage volume, } \\
& A_{b}=\text { infiltrating area, and } \\
& \alpha \text { and } \beta=\text { unit conversion factors. }
\end{aligned}
$$

The maximal value of Eq. 15 is achieved by setting its first derivative with respect to $T_{d}$ equal to zero, and it results:

$\frac{d V_{d}}{d T_{d}}=\left\{C A \propto\left[\frac{-n T_{d}}{\left(T_{d}+b\right)^{n+1}}+\frac{1}{\left(T_{d}+b\right)^{n}}\right]-Q f\left(T_{d}\right)\right\}=0 \quad$ when $T_{d}=T_{m}$

In which $\mathrm{Tm}=$ the design rainfall duration described by Eq. 16. Solution of Eq. 16 is:

$$
T_{m}=\frac{1}{n}\left[\left(T_{m}+b\right)-\left(T_{m}+b\right)^{n+1} \frac{Q}{a \alpha C A} f\left(T_{m}\right)\right]
$$

When the value of $b$ in Eq. 16. Is numerically negligible, the approximate solution of Eq. 16 is:

$$
T_{m}=\left[\frac{2 \alpha a C A(1-n)}{Q f\left(T_{m}\right)}\right]^{\frac{1}{n}}
$$

Using trial and error of Eq. 18 the maximum storage volume, $\mathrm{Vm}$, is

$$
V_{m}=\alpha C I_{m} A T_{m}-Q F\left(T_{m}\right) \quad \text { when } T_{d}=T_{m}
$$

The average infiltration rate, $\mathrm{f}$, through the storm duration is: 


$$
f=\frac{F\left(T_{m}\right)}{T_{m}}
$$

Where

$$
F\left(T_{m}\right)=\text { Total Infiltration depth }
$$

\section{SIZING INFILTRATION BASED GREEN INFRASTRUCTURE}

The above procedure yields a storage volume based on the surface hydrology without taking the subsurface condition into consideration. If the soil infiltration rate at the land surface is higher than the underground seepage rate, the system is backed up and may even cause a failure in the operation. To be conservative, the water storage volume in soil pores can serve as a limit for the water depth in the basin (Geberemariam, 2016; Guo, 2004; Maniquiz et al 2010; Mein \& Larson, 1973; Miles \& Band, 2015; Pitt \& Voorhees 2010; Shuster et al. 2017; Stafford et al, 2015).

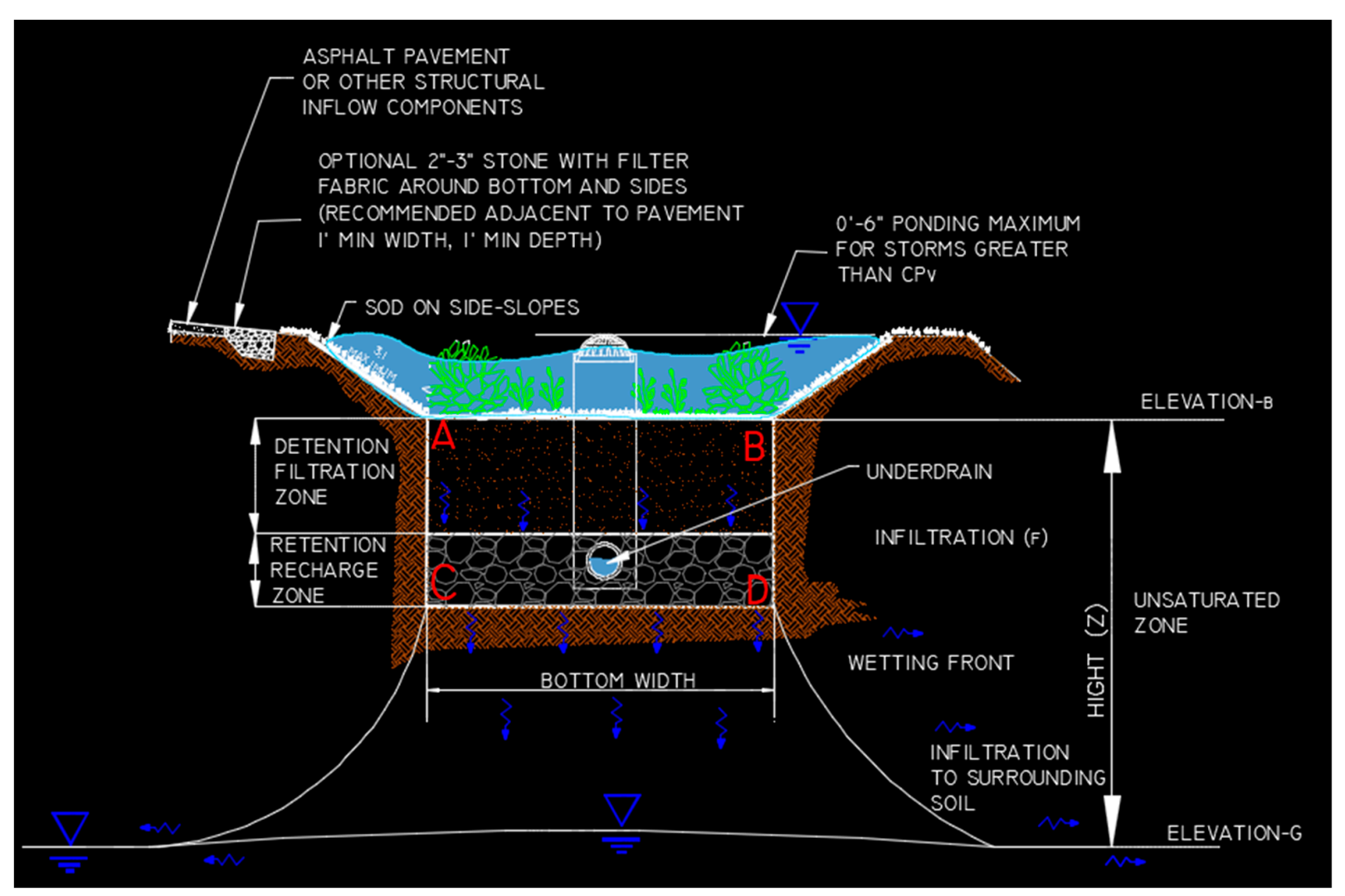

Figure-1 Typical Bio-Retention Infiltration based Green Infrastructure

The sample plan view of Infiltration based Green Infrastructure in Figure-1, shows the infiltrating water begins with a vertical downward velocity through the unsaturated zone underneath the basin. As the soil water content increases, the diffusive nature of the wetting front results in flow movements in both vertical and lateral directions (Brooks et al., 1964; Cannavo et al. 2018; Chu, et al 2018; Ellis, 2000; Mantoglou \& Gelhar 1987; Kavvas et al 2017). As soon as the seepage 
flow reaches the local groundwater table, the soil medium beneath the basin becomes saturated and the seepage flow radially disperses into groundwater. Although many studies used the concept of potential function to investigate the vertical seepage flow and the associated water mounding effect (Griffin \& Warrington 1988, Guira, 2018)., this study applies stream function to describe the movement of the seepage flow through the soil medium. With the consideration of vertical and radial movements, the potential flow model using stream function is developed for the infiltrating flow under a parabolic infiltration basin as (Guo, 1998 and 2001) $)$ as shown in figure-1 above.

Infiltration of water into the soil, like many other flow processes in porous media, is governed by the Richards soil moisture diffusion equation (Celia et al. 1990; Fredlund et al. 1994; Jury et al. 2018; List \& Radu 2016; Pachepsky et al. 2003). According to the diffusion theory, (Green and Ampt, 1911) the seepage flow through the soil medium in Figure 1 can be described as:

$$
\frac{\partial \theta}{\partial t}+\frac{\partial f}{\partial z}=0
$$

in which $\theta=$ soil moisture content, $\mathrm{t}=$ elapsed time, $\mathrm{f}=$ infiltration rate, and $\mathrm{z}=$ vertical distance below the basin. Consider the soil medium between the basin bottom and groundwater table as a control volume. The finite difference form of Eq. 11 is:

$$
\Delta \theta=\frac{\Delta f \Delta t}{\Delta z}
$$

As illustrated in Figure 1, the value of $\Delta \theta$ is the difference between the soil initial and saturated moisture contents. The value of $\Delta z$ is the depth of the soil medium beneath the basin. The value of $\Delta \mathrm{f}$ is equal to the infiltration rate from the basin because there is no recharge to the groundwater table before the wetting front reaches the groundwater table. As a result, Eq. 21 becomes:

$$
\left(\theta_{S}-\theta_{0}\right)=\frac{(f-0)\left(T_{d}-0\right)}{\left(z_{b}-Z_{g}\right)}=\frac{T_{d} f}{Z}
$$

in which $\theta \mathrm{s}=$ soil porosity, $\theta \mathrm{o}=$ soil initial water content, $\mathrm{Zb}=$ elevation at basin bottom, $\mathrm{Zg}=$ elevation of groundwater table, $\mathrm{Td}=$ drain time, and $\mathrm{Z}=$ distance to groundwater table. Rearranging Eq. 23, the drain time at the basin site is derived as:

$$
T_{d}=\frac{Z\left(\theta_{S}-\theta_{0}\right)}{f}
$$

Eq. 24 indicates that the drain time of an infiltration basin is dictated by the storage capacity in the soil pores and the infiltration rate. And the water storage volume in the soil pores is equivalent to:

$$
d=Z\left(\theta_{s}-\theta_{0}\right)
$$

in which $d=$ equivalent water depth in soil pores. Eq. 25 sets the limit for the water depth in the 
basin. As a result, the footprint surface area of the basin is:

$$
A_{b}=\frac{V_{m}}{Z\left(\theta_{S}-\theta_{0}\right)}
$$

Eq. 19 defines the required storage volume in the basin; Eq. 25 sets the maximum water depth in the basin, Eq. 26 defines the minimum basin bottom area; and Eq. 24 calculates the drain time to release the stored volume. The above design procedure applies to the soil mediums under an unsaturated condition. During an event, the storm water quality control basin may saturate the soil mediums. It is important to understand that the soil medium beneath a retention basin with a permanent pool or a long-term groundwater recharging pond would have saturated already. Under a saturated condition, the major concern in design is no longer the basin geometry, but the basin sub-surface geometry (Alley et al, 2002; Healy, 2010; Tedoldi et al 2016) In other word, we have to make sure that the infiltrating water rate can be sustained by the underground hydraulic gradient and conductivity.

\section{EVALUATION OF THE LONG-TERM SUSTAINABLE PERFORMANCE EFFICIENCY}

To evaluate the long-term sustainable of the infiltration based stormwater management system, the designer should analyses the soil medium saturation effect that could reduce the basin infiltration efficiency. As illustrated in Figure-1, the process of infiltration begins with a vertical downward velocity through the unsaturated zone underneath the basin. As the soil water content increases, the diffusive nature of the wetting front results in flow movements in both vertical and lateral directions (Sharma et al 2018). If the vertical flow through the soil medium is slower than the infiltration rate of the natural soil underneath the infiltration basin, the excess inflow will cause water mounting effect that may back up the system to cause a failure, prolonged draining operation, and minimizing the life-cycle of the basin. Therefore, an infiltrating basin must be designed under the constraints of the soil pore storage capacity before saturation and the soil conveyance capacity after saturation (Barrett, 2008; Geberemariam, 2016 and 2017. Guo \& Gao 2016; Haverkamp et al. 1977; Saraswat et al 2016; Yang \& Chui 2018).

Most of the time the evaluation of the long-term sustainability of the infiltration based stormwater management system based on I. analyzing the drain time II. Hydrologic Effectiveness III. Required saturated depth and IV. depth of the trench below the underdrain pipe as follows: -

\section{Analyzing The Drain Time:}

Soils must be sufficiently permeable to ensure that collected runoff can infiltrate quickly enough to reduce the potential for flooding and mosquito breeding (i.e. water ponding for no more than four days) (Hazelton \& Murphy, 2011). Soils with lower hydraulic conductivities do not necessarily preclude the use of infiltration systems, but the size of the required system may typically become prohibitively large, or a more complex design approach may be required, such as including a slow drainage outlet system. Eq. 24 above indicates that the drain time of an infiltration basin is dictated by the storage capacity in the soil pores and the infiltration rate (Staddon et al 2018). 
II. Hydrologic Effectiveness:

The hydrologic effectiveness of an infiltration system defines the proportion of the mean annual runoff volume that infiltrates (Holman-Dodds et al 2003). For a given catchment area and meteorological conditions, the hydrologic effectiveness of an infiltration system is determined by the combined effect of the nature/ quantity of runoff, the 'detention volume', in-situ soil hydraulic conductivity and 'infiltration area (Bracken \& Croke 2007).

The hydrologic effectiveness of an infiltration system requires long term continuous simulation which can be undertaken using the Model for Urban Stormwater Improvement Conceptualization (MUSIC) (CRCCH 2005). However, in most situations, where a number of the design considerations can be fixed (i.e. frequency of runoff, depth of detention storage, saturated hydraulic conductivity), hydrologic effectiveness curves can be generated and used as the design tool for establishing the infiltration system size (Davis, 2005; Davis et al 2009; Elliott \& Trowsdale 2007).

III. Depth of the Trench Below the Underdrain Pipe:

The depth of the trench below the underdrain pipe is dependent on the native soil infiltration rate, porosity (void space ratio) of the gravel storage layer media (i.e., aggregate material used in the stone reservoir) and the targeted time period to achieve complete drainage between storm events. The maximum allowable depth below the pipe can be calculated using the following equation (Afrin et al 2016; Irvine \& Kim, 2018; Murphy, 2013; Kim et al 2019).

Where:

$$
D=\frac{i * T * c f}{\eta * s}
$$

$$
\begin{aligned}
& \mathrm{D}=\text { Maximum stone trench depth below pipe (in) } \\
& \mathrm{I}=\text { Infiltration rate for native soils (in/hr.) } \\
& \mathrm{C}=\text { clogging factor }(0.5) \\
& \eta=\text { Void space ratio for aggregate used (typically } 0.4 \text { clear stone) } \\
& \mathrm{S}=\text { Minimum safety correction factor } \\
& \mathrm{T}=\text { Time to drain (design for } 48 \text {-hour time to drain is recommended) }
\end{aligned}
$$

The designer should keep in mind that the determining factor for recharge systems is the surrounding soil's ability to accept water, not the pipe's ability to deliver water. Although the perforations in the pipe determine the allowable area at which water can be released, it is the soil's ability to accept the water that is the determining factor in designing recharge systems.

\section{DESIGN EXAMPLE -1}

A 20-lot subdivision in which on-lot structural BMPs provide volume and infiltration for the net increase in volume for the 10-year storm event. Peak rate calculations are developed using techniques described by Eq. 12 (Chicago Method) with $\mathrm{a}=96.84, \mathrm{~b}=15.88$ and $\mathrm{n}=0.7952$. the 20-lot subdivision of 5.0 acre is to be developed with a runoff coefficient of 0.75 . The 10-year storm runoff 
from this watershed will drain into $125-\mathrm{ft}$. by 20 -ft. infiltration based green infrastructure basin. The infiltration rates of the basin are: $\mathrm{fo}_{\mathrm{o}}=2.50 \mathrm{inch} / \mathrm{hr}$., $\mathrm{fc}=0.5 \mathrm{inch} / \mathrm{hr}$., and the time constant $\mathrm{k}=0.40$ $/ \mathrm{hr}$. Based on the given information, calculate the design storm duration (min), the required detention volume (ac-ft.), the total infiltration depth (inch), and the bottom area of the basin (ac) assume $\alpha$ and $\beta$ are 70 and 1/12 respectively. The following problem can be solved using Eq. 2,15 and 17: -

I. calculating the design storm duration ( $\mathrm{min})$, using the given data

$$
T_{m}=\frac{1}{0.7952}\left[\left(T_{m}+15.88\right)-\left(T_{m}+15.88\right)^{0.7952+1} \frac{\frac{1}{12} * A_{b}}{96.84 * 70 * 0.75 * 5} f\left(T_{m}\right)\right]
$$

Where : $f\left(T_{m}\right)=1.2+(4.5-1.2) e^{-\frac{T_{m}}{60^{*} 6.5}} \quad$ Substituting these variables into Equations will yield $T_{m}=250.00$ minute

II. Calculating the total infiltration depth (inch), and the bottom area of the basin (ac)

$$
\begin{aligned}
& F(t)=\int f d t=f_{c} t+\frac{\left(f_{0}-f_{c}\right)}{k}\left(1-e^{-k t}\right) \text { and } A_{b}=\frac{40 * 100}{43560} \cong 0.092 a c \\
& F(t)=0.5(t)+\frac{(2.5-0.5)}{0.4}\left(1-e^{-0.4(t)}\right) \Rightarrow 6.14 \text { in }
\end{aligned}
$$

III. Calculating the required detention volume (ac-ft.),

$$
V_{m}=\alpha C I_{m} A T_{m}-\beta Q F\left(T_{m}\right) \quad \text { when } T_{d}=T_{m}
$$

Substituting these variables into Eq. 2, 15, 17 and 19 yields the design storm duration of $T_{m}=$ 250.00 minute. The total infiltration depth, $\mathrm{F}\left(\mathrm{T}_{\mathrm{m}}\right)=6.14 \mathrm{in}$, the calculated bottom area of the basin = $0.092 \mathrm{ac}$ and the required detention volume for this case is 0.737 acre-ft.

\section{DESIGN EXAMPLE -2}

At the project site of Example 1, the soil porosity is 0.50 and has initial water content of 0.20 . The distance to the local groundwater table is 8 feet. Design the basin geometry for storage volume of 0.737 acre-ft. calculated in example-1. Calculate the Maximum stone trench depth below underdrain pipe (in) assume that the void space ratio for clear stone aggregate used is 0.4 .

Under the saturated condition, the water storage volume in the 8-ft. soil medium is:

$$
d=8 f t . *(0.50-0.20)=2.40 \text { feet of water }
$$


Assuming that the basin is designed to have the brim-full depth (filled with something to the point of overflowing) of 2.40 feet, the basin area is determined as:

$$
A_{b}=\frac{0.737}{2.40} \cong 0.31 \text { acre }-f t
$$

The final infiltration rate is $0.5 \mathrm{inch} / \mathrm{hr}$. in Example 1. Therefore, the drain time is:

$$
T_{d}=\frac{2.4 * 12}{0.5} \cong 36 h r
$$

Calculating the Maximum stone trench depth below underdrain pipe (in).

Using Eq. 27 the Maximum stone trench depth below underdrain pipe (in) is

$$
D=\frac{i * T * c f}{\eta * s}=\frac{0.5 * 36 * 0.5}{0.4 * 05}=45 \mathrm{in} \cong \text { use } 3.75 \mathrm{ft}
$$

\section{DESIGN EXAMPLE -3}

Given a circular infiltration basin has a diameter of $50.0 \mathrm{ft}$. The groundwater table at the site is 10.0 feet. The basin will have a layer of loamy sand lining that has an infiltration rate of $1.80 \mathrm{inch} / \mathrm{hr}$. The coefficient of permeability for the native soil is found to be $0.75 \mathrm{inch} / \mathrm{hr}$. Evaluate the sustainability of the proposed infiltration based green infrastructure basin operation, the required saturated distance and suggest that weather the proposed basin lining materials infiltration rate shall be maintained or need revision

Given

Radious of the GI basin $=r_{o}=\frac{50}{2}=25 f t$. and $f=1.80 \frac{\mathrm{in}}{\mathrm{hr}}$

Where: -

$K_{r}=K y=K=0.75 \frac{i n}{h r}$

$K_{r}=$ Hydraulic conductivity in the radial direction

Ky $=$ Coefficient of vertical permeability

$K=$ Coefficient of permeability

$Q=f \pi r^{2}=\frac{1.80}{12 * 3600} * 3.1416 *(25)^{2}=0.08 \mathrm{cfs}$

$\omega=\frac{1.80}{0.75}=2.32 \quad$ where $\omega=\frac{f}{K_{r}}$

The ratio of $\frac{H}{r_{0}}=\sqrt{\frac{2.32 * \ln (2.32)}{2\left((2.32)^{2}-1\right)}}=0.471$ or $H=11.78 f t$ 


$$
\text { The ratio of } \frac{D}{r_{0}}=2.32 \sqrt{\frac{2.32 * \ln (2.32)}{2\left((2.32)^{2}-1\right)}}=1.09 \text { or } D=27.25 \mathrm{ft}
$$

The required saturated depth calculated as

$$
\frac{Y_{0}}{r_{0}}=\frac{D-H}{Y_{0}}=\stackrel{\text { yields }}{\longrightarrow} Y_{0}=27.25-11.78=15.33 \mathrm{ft} .
$$

The required saturated distance is greater than the available (15.33>10.00 ft.). Therefore, the design infiltration rate or the design radius of the GI must be reduced.

\section{CONCLUSION}

On this paper we assessed what contributes to the failure of most recently constructed infiltration based BMP's such as porous pavements, riprap trenches, infiltration beds, retention pools, detention systems, wetlands, and drywells. Examination of the current design approaches further revealed that the serious negligence of site constraints that have caused flooding, ponding, prolonged movement of surface water, and frequent clogging, etc. our work suggests alternative approaches using finite difference method to design sustainable infiltration based stormwater management system that integrates all constraints such as underlying soil permeability(k), Drain Time (Td), Hydrologic Effectiveness, and the depth of the trench below the underdrain pipe.

Finally, the evaluation of the sustainability of the proposed infiltration based stormwater management operation shall be dependent on the native soil infiltration rate, porosity (void space ratio) of the gravel storage layer media (i.e., aggregate material used in the stone reservoir) and the targeted time period to achieve complete drainage between storm events.

\section{REFERENCES}

1. Afrin, T., Kaye, N. B., Khan, A. A., \& Testik, F. Y. (2016). Parametric study of perforated pipe underdrains surrounded by loose aggregate. Journal of Hydraulic Engineering, 142(12), 04016066.

2. Afrin, T., Khan, A. A., Kaye, N. B., \& Testik, F. Y. (2016). Numerical model for the hydraulic performance of perforated pipe underdrains surrounded by loose aggregate. Journal of Hydraulic Engineering, 142(8), 04016018.

3. Al-Hamati, A. A., Ghazali, A. H., \& Mohammed, T. A. (2010). Determination of storage volume required in a sub-surface stormwater detention/retention system. Journal of Hydroenvironment Research, 4(1), 47-53.

4. Alley, W. M., Healy, R. W., LaBaugh, J. W., \& Reilly, T. E. (2002). Flow and storage in groundwater systems. science, 296(5575), 1985-1990. 
5. Barrett, M. E. (2008). Comparison of BMP performance using the international BMP database. Journal of Irrigation and Drainage Engineering, 134(5), 556-561.

6. Bauer, S. W. (1974). A modified Horton equation for infiltration during intermittent rainfall. Hydrological Sciences Journal, 19(2), 219-225.

7. Beven, K. (2004). Robert E. Horton's perceptual model of infiltration processes. Hydrological processes, 18(17), 3447-3460.

8. Bouwer, H, Back, J.T., and Oliver, J.M. (1999), "Predicting Infiltration and Ground-water Mounds for Artificial Recharge". ASCE J. of Hydrologic Engineering, Vol 4, No. 4, October, pp 350-357

9. Bracken, L. J., \& Croke, J. (2007). The concept of hydrological connectivity and its contribution to understanding runoff-dominated geomorphic systems. Hydrological processes, 21(13), 1749-1763.

10. Brooks, R.H., and Corey, A.T. (1964). "Hydraulic properties of Porous Media." Hydrologic Paper No. 3, Colorado State University, Ft. Collins, Colorado.

11. Cannavo, P., Coulon, A., Charpentier, S., Béchet, B., \& Vidal-Beaudet, L. (2018). Water balance prediction in stormwater infiltration basins using 2-D modeling: An application to evaluate the clogging process. International Journal of Sediment Research.

12. Celia, M. A., Bouloutas, E. T., \& Zarba, R. L. (1990). A general mass-conservative numerical solution for the unsaturated flow equation. Water resources research, 26(7), 1483-1496.

13. Chu, X., Jia, X., \& Liu, Y. (2018). Quantification of wetting front movement under the influence of surface topography. Soil Research.

14. Daly, E., Deletic, A., Hatt, B. E., \& Fletcher, T. D. (2012). Modelling of stormwater biofilters under random hydrologic variability: a case study of a car park at Monash University, Victoria (Australia). Hydrological Processes, 26(22), 3416-3424.

15. Davis, A. P. (2005). Green engineering principles promote low-impact development.

16. Davis, A. P., Hunt, W. F., Traver, R. G., \& Clar, M. (2009). Bioretention technology: Overview of current practice and future needs. Journal of environmental engineering, 135(3), 109-117.

17. Elliott, A. H., \& Trowsdale, S. A. (2007). A review of models for low impact urban stormwater drainage. Environmental modelling \& software, 22(3), 394-405.

18. Ellis, J. B. (2000). Infiltration systems: a sustainable source-control option for urban stormwater quality management? Water and Environment Journal, 14(1), 27-34.

19. Emerson, C. H., \& Traver, R. G. (2008). Multiyear and seasonal variation of infiltration from storm-water best management practices. Journal of irrigation and drainage Engineering, 134(5), 598-605.

20. Ferguson, Bruce K., (1990). "Role of the Long-term Water Balance in Management of Storm Water Infiltration," J. of Environmental Management, Vol 30, pp 221-233.

21. Fredlund, D. G., Xing, A., \& Huang, S. (1994). Predicting the permeability function for unsaturated soils using the soil-water characteristic curve.Canadian Geotechnical 
Journal, 31(4), 533-546.

22. Geberemariam, T. (2016). Post Construction Green Infrastructure Performance Monitoring Parameters and Their Functional Components. Environments, 4(1), 2.

23. Geberemariam, T.K. Deterministic and Probabilistic Engineering Cost Estimating Approaches for Complex Urban Drainage Infrastructure Capital Improvement (CIP) Programs. Preprints 2018, 2018110259 (doi: 10.20944/preprints201811.0259.v1).

24. Green, W. H., \& Ampt, G. A. (1911). Studies on Soil Phyics. The Journal of Agricultural Science, 4(1), 1-24.

25. Griffin, D.M. Jr., and Warrington, R.O. (1988). "Examination of 2-D Groundwater Recharge Solution.", ASCE J. of Irrigation and Drainage Engineering, Vol. 114, No. 4, Nov., pp 691704

26. Guira, m. (2018). Numerical modeling of the effects of land use change and irrigation on streamflow depletion of frenchman creek, nebraska.

27. Guo, J. C. (1999). Detention storage volume for small urban catchments. Journal of water resources planning and management, 125(6), 380-382.

28. Guo, J. C., \& Urbonas, B. (1996). Maximized detention volume determined by runoff capture ratio. Journal of Water Resources Planning and Management, 122(1), 33-39.

29. Guo, James C.Y. (2001). “Design of Circular Infiltration Basin Under Water Mounding Effects," ASCE J. of Water Resources Planning and Management, Vol 127, No.1, Jan/Feb.

30. Guo, James C.Y. (2002). “Overflow Risk of Storm Water BMP Basin Design," ASCE J. of Hydrologic Engineering, Vol 7, No. 6, Nov.

31. Guo, James C.Y. (2003). "Design of Infiltrating Basin by Soil Storage and Conveyance Capacities," IWRA International J. of Water, Vol 28, No. 4, December.

32. Guo, James C.Y. (2004). "Hydrology-Based Approach to Storm Water Detention Design Using New Routing Schemes," ASCE J. of Hydrologic Engineering, Vol 9, No. 4, July/August

33. Guo, James C.Y. and Hughes, William. (2001). "Runoff Storage Volume for Infiltration Basin," ASCE J. of Irrigation and Drainage Engineering, Vol 127, No. 3, May/June.

34. Guo, James C.Y. and Urbonas, Ben. (2002). "Runoff Capture and Delivery Curves for Storm Water Quality Control Designs," ASCE J. of Water Resources Planning and Management, Vol 128, Vo. 3, May/June.

35. Guo, Y., \& Gao, T. (2016). Analytical equations for estimating the total runoff reduction efficiency of infiltration trenches. Journal of Sustainable Water in the Built Environment, 2(3), 06016001.

36. Haverkamp, R., Vauclin, M., Touma, J., Wierenga, P. J., \& Vachaud, G. (1977). A Comparison of Numerical Simulation Models For One-Dimensional Infiltration 1. Soil Science Society of America Journal, 41(2), 285-294.

37. Hazelton, P., \& Murphy, B. (2011). Understanding soils in urban environments. Csiro 
publishing.

38. Healy, R. W. (2010). Estimating groundwater recharge. Cambridge University Press.

39. Holman-Dodds, J. K., Bradley, A. A., \& Potter, K. W. (2003). Evaluation of Hydrologic Benefits Of Infiltration Based Urban Storm Water Management 1. JAWRA Journal of the American Water Resources Association, 39(1), 205-215.

40. Huyakorn, P. S., Thomas, S. D., \& Thompson, B. M. (1984). Techniques for making finite elements competitive in modeling flow in variably saturated porous media. Water Resources Research, 20(8), 1099-1115.

41. Irvine, J. L., \& Kim, A. S. (2018). Understanding bioswale as a small water and wastewater treatment plant: A theoretical review. Desalination and Water Treatment, 1, 15.

42. Jayasooriya, V. M., \& Ng, A. W. M. (2014). Tools for modeling of stormwater management and economics of green infrastructure practices: a review. Water, Air, $\mathcal{E}$ Soil Pollution, 225(8), 2055.

43. Jury, W. A., \& Stolzy, L. H. (2018). Soil physics. In Handbook of Soils and Climate in Agriculture (pp. 131-158). CRC Press.

44. Kavvas, M. L., Ercan, A., \& Polsinelli, J. (2017). Governing equations of transient soil water flow and soil water flux in multi-dimensional fractional anisotropic media and fractional time. Hydrology and Earth System Sciences, 21(3), 1547-1557.

45. Keifer, C. J., \& Chu, H. H. (1957). Synthetic storm pattern for drainage design. Journal of the hydraulics division, 83(4), 1-25.

46. Kim, H., Mallari, K. J. B., Baek, J., Pak, G., Choi, H. I., \& Yoon, J. (2019). Considering the effect of groundwater on bioretention using the Storm Water Management Model. Journal of environmental management, 231, 1270-1276.

47. Krvavica, N., Jaredić, K., \& Rubinić, J. (2018). Methodology for defining the design storm for sizing the infiltration system. Gradevinar, 70(08.), 657-669.

48. Kunze, R. J., \& Nielsen, D. R. (1982). Finite-difference solutions of the infiltration equation. Soil Science, 134(2), 81-88.

49. Le Coustumer, S., \& Barraud, S. (2007). Long-term hydraulic and pollution retention performance of infiltration systems. Water science and Technology, 55(4), 235-243.

50. Lewellyn, C., Lyons, C. E., Traver, R. G., \& Wadzuk, B. M. (2015). Evaluation of seasonal and large storm runoff volume capture of an infiltration green infrastructure system. Journal of Hydrologic Engineering, 21(1), 04015047.

51. List, F., \& Radu, F. A. (2016). A study on iterative methods for solving Richards' equation. Computational Geosciences, 20(2), 341-353.

52. Liu, W., Chen, W., \& Peng, C. (2015). Influences of setting sizes and combination of green infrastructures on community's stormwater runoff reduction. Ecological Modelling, 318, 236244.

53. Maniquiz, M. C., Lee, S. Y., \& Kim, L. H. (2010). Long-term monitoring of infiltration trench 
for nonpoint source pollution control. Water, Air, \& Soil Pollution, 212(1-4), 13-26.

54. Mantoglou, A., \& Gelhar, L. W. (1987). Effective hydraulic conductivities of transient unsaturated flow in stratified soils. Water Resources Research, 23(1), 57-67.

55. Mein, R. G., \& Larson, C. L. (1973). Modeling infiltration during a steady rain. Water resources research, 9(2), 384-394.

56. Miles, B., \& Band, L. E. (2015). Green infrastructure stormwater management at the watershed scale: urban variable source area and watershed capacitance. Hydrological Processes, 29(9), 2268-2274.

57. Murphy, P. (2013). The hydraulic performance of perforated pipe under-drains surrounded by loose aggregate.

58. Murphy, P., Kaye, N. B., \& Khan, A. A. (2014). Hydraulic performance of aggregate beds with perforated pipe underdrains flowing full. Journal of Irrigation and Drainage Engineering, 140(8), 04014023.

59. Overton, D. E., \& Meadows, M. E. (2013). Stormwater modeling. Elsevier.

60. Pachepsky, Y., Timlin, D., \& Rawls, W. (2003). Generalized Richards' equation to simulate water transport in unsaturated soils. Journal of Hydrology, 272(1-4), 3-13.

61. Philip, J. R. (1969). Theory of infiltration. In Advances in hydroscience (Vol. 5, pp. 215-296). Elsevier.

62. Pitt, R., \& Voorhees, J. (2010). Integrated modeling of green infrastructure components in an area served by combined sewers. In Low Impact Development 2010: Redefining Water in the City (pp. 1617-1630).

63. Saraswat, C., Kumar, P., \& Mishra, B. K. (2016). Assessment of stormwater runoff management practices and governance under climate change and urbanization: An analysis of Bangkok, Hanoi and Tokyo. Environmental Science E Policy, 64, 101-117.

64. Sharma, A., Gardner, T., \& Begbie, D. (Eds.). (2018). Approaches to Water Sensitive Urban Design: Potential, Design, Ecological Health, Urban Greening, Economics, Policies, and Community Perceptions. Woodhead Publishing.

65. Shuster, W. D., Darner, R. A., Schifman, L. A., \& Herrmann, D. L. (2017). Factors Contributing to the Hydrologic Effectiveness of a Rain Garden Network (Cincinnati OH USA). Infrastructures, 2(3), 11.

66. Silveira, A. L. L. D. (2016). Cumulative equations for continuous time Chicago hyetograph method. RBRH, 21(3), 646-651.

67. Smith, G. D. (1985). Numerical solution of partial differential equations: finite difference methods. Oxford university press.

68. Staddon, C., Ward, S., De Vito, L., Zuniga-Teran, A., Gerlak, A. K., Schoeman, Y., ... \& Booth, G. (2018). Contributions of green infrastructure to enhancing urban resilience. Environment Systems and Decisions, 38(3), 330-338.

69. Stafford, N., Che, D., \& Mays, L. W. (2015). Optimization model for the design of infiltration 
basins. Water Resources Management, 29(8), 2789-2804.

70. Tedoldi, D., Chebbo, G., Pierlot, D., Kovacs, Y., \& Gromaire, M. C. (2016). Impact of runoff infiltration on contaminant accumulation and transport in the soil/filter media of Sustainable Urban Drainage Systems: A literature review. Science of the Total Environment, 569, 904-926.

71. Verma, S. C. (1982). Modified Horton's infiltration equation. Journal of Hydrology, 58(3-4), 383-388.

72. Voskamp, I. M., \& Van de Ven, F. H. M. (2015). Planning support system for climate adaptation: Composing effective sets of blue-green measures to reduce urban vulnerability to extreme weather events. Building and Environment, 83, 159-167.

73. Warren, W. M. (1974). RETENTION BASIN FAILURES IN CARBONATE TERRANES 1. JAWRA Journal of the American Water Resources Association, 10(1), 22-31.

74. Yang, Y., \& Chui, T. F. M. (2018). Rapid assessment of hydrologic performance of low impact development practices under design storms. JAWRA Journal of the American Water Resources Association, 54(3), 613-630.

75. Zaidel, J., \& Russo, D. (1992). Estimation of finite difference interblock conductivities for simulation of infiltration into initially dry soils. Water Resources Research, 28(9), 2285-2295.

76. Zhang, S., \& Guo, Y. (2014). Stormwater capture efficiency of bioretention systems. Water resources management, 28(1), 149-168. 